\title{
Hubungan E-Business Dan SCM Dalam Manajemen Internal PT Tsabita Cake \& Bakery
}

\author{
Azifa Habiba*1, Mifta Ardianti' ${ }^{2}$, Jiyestha Aji Dharma Aryasa ${ }^{3}$, Muhammad Amanulloh Mz $^{4}$, \\ Shahnilna Fitrasha Bayastura ${ }^{5}$, Eko Sediyono ${ }^{6}$, Aris Puji Widodo ${ }^{7}$ \\ Magister Sistem Informasi, Sekolah Pascasarjana, Universitas Diponegoro \\ Jalan Prof. Soedarto, SH Tembalang Semarang \\ Email : *1azifahabiba@ students.undip.ac.id, ${ }^{2}$ miftaardianti@ students.undip.ac.id, \\ 3jiyesthaaji@students.undip.ac.id, ${ }^{4}$ muhammadamanullohmz@students.undip.ac.id, \\ ${ }^{5}$ shahnilnafitrasha@students.undip.ac.id, ${ }^{6}$ ekosediyono@lecturer.undip.ac.id, \\ 7arispw@gmail.com
}

\begin{abstract}
Abstrak
Penelitian ini bertujuan untuk menganalisis hubungan e-business dan SCM dalam manajemen internal PT Tsabita Cake \& Bakery karena perusahaan tersebut yang awalnya masih menggunakan sistem manual akhirnya beralih menggunakan SCM dan e-business. Metode yang digunakan adalah pendekatan kuantitatif dan analisis korelasi untuk menganalisis faktor yang mempengaruhinya. Penelitian ini menggunakan faktor hubungan pelanggan, faktor administratif, faktor teknologi, proses produksi, dan hubungan pemasok sebagai variabel. Hasil yang dicapai adalah mengetahui apakah dengan menggunakan SCM dan e-business memberikan pengaruh pada manajemen internal suatu perusahaan. Apakah suatu perusahaan yang sudah menggunakan SCM dan e-business mampu meningkatkan produktivitas perusahaan melalui otomatisasi informasi antara partner dalam supply chain, mengurangi biaya operasional penyimpanan barang serta mengintegrasikan informasi diantara divisi dalam perusahaan. Penelitian ini menggunakan tool $R$ Studio dan melakukan perhitungan menggunakan metode analisis korelasi pearson.
\end{abstract}

Kata Kunci: Manajemen Rantai Pasok, E-Business, Analisis Pearson, Sistem Informasi

Abstract

This study aims to analyze the relationship between e-business and SCM in the internal management of PT Tsabita Cake \& Bakery because the company, which initially still used a manual system, eventually switched to using SCM and e-business. The method used is a quantitative approach and correlation analysis to analyze the factors that influence it. This study uses customer relationship factors, administrative factors, technology factors, production processes, and supplier relationships as variables. The result achieved is knowing whether using SCM and e-business has an effect on the internal management of a company. Is a company that already uses SCM and e-business able to increase company productivity through automating information between partners in the supply chain, reducing operational costs for storing goods and integrating information between divisions within the company. This study uses the $R$ Studio as a tool and performs calculations using the pearson correlation analysis method.

Keywords: Supply Chain Management, E-Business, Pearson Analysis, Information System 


\section{PENDAHULUAN}

Kemajuan teknologi informasi harus didukung oleh kualitas sumber daya manusia sebagai komponen utama dalam suatu perusahaan. Adanya sumber daya manusia yang mumpuni, akan memudahkan pemanfaatan $e$-business sebagai alat komunikasi antara produsen dan konsumen dalam meningkatkan dan memperluas produk suatu perusahaan. E-business dalam sebuah perusahaan mampu memberikan peningkatan dari segi pemasaran, jangkauan kegiatan, dan juga memudahkan proses pertukaran informasi secara real time. Namun tidak semua pelaku usaha siap untuk menerapkan e-business pada perusahaan mereka. Padahal mobilitas manusia yang tinggi menuntut dunia industri dan perdagangan untuk menyediakan layanan yang optimal dan respon cepat. Jawaban dari respon cepat tersebut yaitu perpaduan antara $e$-business dan SCM pada suatu perusahaan.

Selain faktor SDM dan teknologi, faktor manajemen internal juga memberikan dampak terhadap perusahaan. Faktor manajemen internal dipengaruhi oleh proses administrasi dan produksi yang terorganisir rapi di dalamnya. Adanya komputerisasi data pada konsumen dan perusahaan dalam proses administrasi akan menjadikan proses produksi di perusahaan berjalan lebih stabil. Proses produksi yang stabil menghasilkan efisiensi dan proses yang sesuai harapan perusahaan. Hal lain yang perlu diperhatikan adalah manajemen limbah tak terpakai yang harus bisa didaur ulang agar tidak mencemari lingkungan. Selain itu limbah yang banyak terbuang juga mempengaruhi profit suatu perusahaan.

PT Tsabita Cake \& Bakery adalah sebuah perusahaan roti yang berdiri sejak tahun 2006. Lokasi PT Tsabita Cake \& Bakery berada di Solo. Tantangan selalu ada untuk mencapai citacita memiliki toko cake \& bakery yang representatif, yaitu menjadi rujukan snack halal di Solo dan sekitarnya. Tantangan berat adalah sumber daya manusia, bagaimana mendidik dan membawa mereka dari sebuah usaha rumahan yang masih serba longgar menuju sumber daya manusia yang lebih baik dalam sebuah perusahaan yang tertib, disiplin, terjaga produktivitas kerjanya. PT Tsabita Cake \& Bakery berawal dari usaha rumahan yang didirikan di depan teras rumah kontrakan yang akhirnya sekarang memiliki ratusan karyawan dan pabrik yang tersistem secara rapi. Dari tahun 2006 hingga 2015 semua sistem masih berjalan secara manual. Namun sejak tahun 2015 hingga sekarang sistem dari PT Tsabita Cake \& Bakery sudah terkomputasi dengan baik.

Berdasarkan informasi tersebut perlu adanya penelitian lebih lanjut tentang hubungan $e$ business dan Supply Chain Management (SCM) yang sudah diterapkan pada PT Tsabita Cake \& Bakery. Dalam hubungan e-business dan Supply Chain Management (SCM) tentunya dipengaruhi oleh banyak faktor, mulai dari e-business maupun dari SCM. Penelitian ini akan menggunakan faktor hubungan pelanggan, faktor administratif, faktor teknologi, proses produksi, dan hubungan pemasok sebagai variable. Kemudian akan dianalisis menggunakan analisis korelasi.

\subsection{Hubungan E-Business dengan Supply Chain Management (SCM)}

E-Business (Electronic Business) merupakan aktivitas jual beli didalam sebuah layanan internet yang berhubungan dengan proses bisnis dengan interaksi antara penjual dan pembeli melalui input, proses, dan output akan tetapi pada aktivitasnya berbentuk hasil dari penggunaan internet dalam mendukung kegiatan bisnis perusahaan [2] E-Business tidak hanya menjual dan membeli barang dan jasa, akan tetapi model $e$-business juga melayani seluruh aktifitas-aktifitas yang berhubungan dengan bisnis, dengan berkembangnya infrastruktur teknologi informasi maka e-business berkembang menjadi sebuah aktifitas dunia maya yang melibatkan antara penjual dan pembeli dan ada proses saling menguntungkan didalam sistem informasinya, 
bekerja sama dan menjalin relasi dengan berbagai partner bisnis[3]. Definisi $e$-business menurut IBM merupakan pendekatan yang aman, fleksibel dan terintegrasi untuk memberikan nilai bisnis yang berbeda dengan kombinasi dari sistem dan proses yang menjalankan operasi bisnis utama dengan memanfaatkan teknologi internet [4].

SCM merupakan pendekatan yang dapat digunakan untuk mencapai pengintegrasian berbagai perusahaan yang lebih efisien yang mempunyai arti produk dapat diproduksi dengan jumlah yang tepat untuk mencapai cost minimum dari sistem secara keseluruhan serta dapat mencapai service level yang diinginkan [5]. Supply Chain Management juga merupakan salah satu alat paling penting yang digunakan untuk mengembangkan sebuah perusahaan. Dimana terdapat beberapa faktor yang merupakan faktor efektif dalam menentukan supply chain management yaitu, orientasi pelanggan, berbagi pengetahuan, adopsi teknologi informasi (TI), kemitraan, kepemimpinan, pelatihan dan komunikasi. Peranan komunikasi juga merupakan hal penting dalam menentukan kinerja di dalam manufaktur [6]

Kolaborasi antara e-business dan SCM merupakan inti dari keseluruhan bisnis secara digital. SCM dan e-business merupakan kombinasi optimal antara teknologi dan proses bisnis tentang distribusi barang, jasa dan informasi dari pemasok kepada konsumen secara terorganisir dan efisien. Salah satu perusahaan sebesar Intel juga memanfaatkan e-business. Supply Chain Management juga untuk bersaing dengan kompetitornya. Sampai dengan 1998, Intel masih manual dalam berkomunikasi dengan partnernya. Tahun 1997, Intel mulai melakukan perancangan e-business system dengan membentuk tim Virtual Worldwide E-Business Project. Hasilnya lebih dari 50\% pendapatan dan konsumen Intel berasal dari luar Amerika. Pada 2008, Intel melakukan penjualan lebih dari 25 Miliar Dolar diseluruh dunia.[7].

\section{METODE PENELITIAN}

\subsection{Metode Penelitian}

Metode penelitian digunakan sebagai pedoman dalam kegiatan penelitian sehingga dengan menggunakan metode yang tepat maka tujuan penelitian ini dapat tercapai maksimal. Metode penelitian yang digunakan adalah metode pendekatan kuantitatif untuk mengukur hubungan e-business dan SCM berdasarkan faktor - faktor yang mempengaruhinya. Metode penelitian kuantitatif adalah metode penelitian berlandaskan positivisme, digunakan untuk meneliti pada populasi atau sampel tertentu, teknik pengambilan sampel pada umumnya dilakukan secara random [1]. Sedangkan jenis penelitiannya termasuk dalam deskriptif korelasi sebab akibat yang ditujukan untuk mengetahui hubungan e-business dan SCM berdasarkan faktor - faktor yang telah ditentukan pada PT Tsabita Cake \& Bakery. Penelitian ini memiliki 5 (lima) tahapan.

\section{Tahap Studi Pendahuluan}

Pada tahap ini dilakukan identifikasi masalah terkait hubungan e-business dengan SCM dalam manajemen internal pada PT Tsabita Cake \& Bakery. Setelah mengidentifikasi masalah tersebut dibentuk rumusan masalah dan tujuan. Pemilihan PT Tsabita Cake \& Bakery sebagai objek penelitian karena perusahaan tersebut sejak awal berdiri belum menggunakan sistem e-business dan scm. Lalu pada tahun 2015 baru menggunakan SCM yang terintegrasi dengan teknologi informasi. Berdasarkan temuan ini kami ingin melihat bagaimana pengaruh penerapan SCM pada manajemen internal PT Tsabita Cake \& Bakery

\section{Tahap Perencanaan Penelitian}

Pada tahapan perencanaan penelitian, dilakukan proses persiapan data - data yang dibutuhkan dalam kegiatan penelitian dan juga mempersiapkan variabel beserta instrumen penelitian yang sesuai dengan kebutuhan penelitian. 


\section{Tahap Pengumpulan Data}

Pengumpulan data dilakukan dengan pemberian kuesioner kepada karyawan PT Tsabita Cake \& Bakery dari mulai low level bagian produksi, marketing sampai pada top level yaitu bagian manajerial pada PT Tsabita Cake \& Bakery . Pemberian kuesioner mengenai hal yang berhubungan dengan e-business dan SCM berdasarkan studi literatur.

4. Tahap Analisis Data

Pada tahapan analisis data dilakukan proses analisis data yang telah terkumpul. Pada penelitian ini menggunakan metode analisis korelasi dengan menggunakan perangkat lunak analisis data $R$ studio. Analisis korelasi merupakan salah satu jenis pengukuran dalam statistik yang sering digunakan dalam pengolahan data[8]. Menurut A.M Tuttle korelasi adalah analisis kovarian antara dua atau lebih variabel. Data yang diperoleh kemudian dianalisis korelasinya menggunakan metode analisis korelasi pearson dengan rumus :

\section{Keterangan:}

$$
r=\frac{\sum x y-\frac{\left(\sum x \sum y\right)}{n}}{\sqrt{\left(\sum x^{2}-\frac{\left(\sum x\right)^{2}}{n}\right)\left(\sum y^{2}-\frac{\left(\sum y\right)^{2}}{n}\right)}}(1)
$$

$$
\begin{array}{ll}
\mathrm{n} & =\text { banyaknya pasangan data } \mathrm{X} \text { dan } \mathrm{Y} \\
\sum \mathrm{x} & =\text { total jumlah dari variabel } \mathrm{X} \\
\sum \mathrm{y} & =\text { total jumlah dari variabel } \mathrm{Y} \\
\sum \mathrm{x}^{2} & =\text { kuadrat dari total jumlah variabel } \mathrm{X} \\
\sum \mathrm{y}^{2} & =\text { kuadrat dari total jumlah variabel } \mathrm{Y} \\
\sum \mathrm{xy} & =\text { hasil perkalian dari total jumlah variabel } \mathrm{X} \text { dan variabel } \mathrm{Y}
\end{array}
$$

5. Tahap Penarikan Kesimpulan

Pada tahapan ini dilakukan penarikan kesimpulan dari penelitian ini. Penarikan kesimpulan ini berdasarkan hasil analisis korelasi dari pengolahan data yang telah dilakukan.

\subsection{Variabel Penelitian}

Variabel pada penelitian ini menggunakan variabel dependent dan variabel independent.

\section{Variabel Dependent}

Variabel dependent merupakan variabel yang bergantung dan tidak bebas. Variabel ini merupakan akibat yang ditimbulkan oleh sebuah sebab (variabel independent). Variabel dependent pada penelitian ini adalah e-business. Dimensi dari variabel dependent dapat dilihat pada Tabel 1 .

Tabel 1. Dimensi Variabel Dependent

\begin{tabular}{|l|l|l|}
\hline Variabel & \multicolumn{1}{|c|}{ Dimensi } & \multicolumn{1}{c|}{ Studi } \\
\hline \multirow{2}{*}{ E-Business } & Hubungan Pelanggan & Melinda, 2001 \\
\cline { 2 - 3 } & Faktor Adminsitratif & $\begin{array}{l}\text { Fang Wu, Mahajan Vijay } \\
\text { \& Sridhar } \\
\text { Balasubramanian, 2003 }\end{array}$ \\
\hline
\end{tabular}

a. Hubungan Pelanggan merupakan suatu komunikasi perusahaan dengan fokus menyediakan nilai yang optimal bagi pelanggan, bagaimana perusahaan memasarkan kepada mereka, dan juga melalui pemasaran tradisional yang terdiri dari promosi, produk, distribusi dan harga [9]. Pernyataan hubungan pelanggan (HPL) dapat dilihat pada Tabel 2. 
Tabel 2. Pernyataan Hubungan Pelanggan

\begin{tabular}{|l|l|l|}
\hline Kode & \multicolumn{4}{|c|}{ Pernyataan } \\
\hline HPL1 & $\begin{array}{l}\text { Perusahaan kami senantiasa berinteraksi dengan pelanggan untuk } \\
\text { menetapkan standar (standar pengiriman, standar dalam merespon } \\
\text { pelanggan). }\end{array}$ \\
\hline HPL2 & $\begin{array}{l}\text { Perusahaan kami senantiasa mencari tahu apa keinginan pasar dimasa } \\
\text { depan (future expectation). }\end{array}$ \\
\hline HPL3 & $\begin{array}{l}\text { Perusahaan kami senantiasa memfasilitasi pelanggan yang } \\
\text { membutuhkan bantuan / mengadukan komplain }\end{array}$ \\
\hline HPL4 & $\begin{array}{l}\text { Perusahaan kami secara rutin melakukan evaluasi kinerja serta } \\
\text { berusaha untuk menanggapi keluhan dari pelanggan secara terbuka }\end{array}$ \\
\hline HPL5 & $\begin{array}{l}\text { Perusahaan kami senantiasa melakukan pengiriman barang kepada } \\
\text { konsumen tepat waktu dibandingkan dengan pesaing lain }\end{array}$ \\
\hline
\end{tabular}

b. Faktor Administratif melakukan atau memfasilitasi berbagai kegiatan yang berkaitan dengan akuntansi keuangan dan manajerial, sumber daya manusia dan manajemen tunjangan karyawan, penggantian biaya perjalanan, dan batasan bisnis [12]. Pernyataan faktor administratif (FA) dapat dilihat pada Tabel 2.

Tabel 3. Pernyataan Faktor Administratif

\begin{tabular}{|c|c|}
\hline Kode & Pernyataan \\
\hline \multicolumn{2}{|r|}{ Faktor Administratif } \\
\hline FA1 & Adanya komputerisasi data konsumen pada perusahaan kami. \\
\hline FA2 & Kami membiasakan karyawan agar tertib administrasi \\
\hline FA3 & $\begin{array}{l}\text { Perusahaan kami secara rutin melakukan evaluasi kinerja serta } \\
\text { berusaha untuk menanggapi keluhan dari karyawan secara terbuka }\end{array}$ \\
\hline
\end{tabular}

2. Variabel Independent

Variabel independent merupakan variabel yang tidak bergantung dan bebas. Variabel ini merupakan sebab dan mengarah pada variabel dependent. Variabel independent pada penelitian ini adalah supply chain management. Dimensi dari variabel independent dapat dilihat pada Tabel 4.

Tabel 4. Dimensi Variabel Independent

\begin{tabular}{|l|l|l|}
\hline \multicolumn{1}{|c|}{ Variabel } & \multicolumn{1}{|c|}{ Dimensi } & \multicolumn{1}{c|}{ Studi } \\
\hline \multirow{2}{*}{$\begin{array}{c}\text { Supply Chain } \\
\text { Management }\end{array}$} & Faktor Teknologi & Suhari, Y.,2011 \\
\cline { 2 - 3 } & Proses Produksi & Yamit, Zulian. 2011 \\
\cline { 2 - 3 } & Hubungan Pemasok & Melinda. 2001 \\
\hline
\end{tabular}

a. Faktor Teknologi merupakan hal yang paling diperlukan dalam penerapan Supply Chain Management dengan e-business. Perusahaan yang tidak menggunakan teknologi dan tidak 
mengikuti perkembangan pasar akan kehilangan kemampuan untuk berperan serta sebagai perusahaan era digital [10]. Pernyataan faktor teknologi (FT) dapat dilihat pada Tabel 5.

Tabel 5. Pernyataan Faktor Teknologi

\begin{tabular}{|c|c|}
\hline Kode & ataan \\
\hline & Faktor Teknologi \\
\hline FT1 & $\begin{array}{l}\text { Adanya SCM pada perusahaan kami mempengaruhi kecepatan } \\
\text { produksi }\end{array}$ \\
\hline FT2 & $\begin{array}{lcccc}\text { Penggunaan } & \text { SCM } & \text { membuat kami } & \text { bergerak cepat } & \text { dalam } \\
\text { mengembangkan produk baru dibandingkan dengan pesaing } & \end{array}$ \\
\hline FT3 & $\begin{array}{l}\text { luruh karyawan dengan mudahnya mempelajari sistem SCM yang } \\
\text { a pada perusahaan kami }\end{array}$ \\
\hline FT4 & $\begin{array}{l}\text { Selalu ada mainte } \\
\text { mengantisipasi ke }\end{array}$ \\
\hline
\end{tabular}

b. Proses Produksi merupakan proses pengubahan (transformasi) dari bahan atau komponen (input) menjadi produk lain yang mempunyai nilai lebih tinggi atau dalam proses terjadi penambahan nilai [11]. Pernyataan faktor Produksi (FP) dapat dilihat pada Tabel 6.

Tabel 6. Pernyataan Faktor Produksi

\begin{tabular}{|l|l|}
\hline Kode & \multicolumn{1}{|c|}{ Proses Produksi } \\
\hline \multicolumn{2}{|c|}{} \\
\hline PP1 & $\begin{array}{l}\text { Proses produksi yang terjadi sejauh ini tidak menghasilkan banyak } \\
\text { waste / limbah yang menyebabkan kerusakan lingkungan atau } \\
\text { merugikan pihak lain }\end{array}$ \\
\hline PP2 & Perusahaan sudah melakukan proses produksi secara efektif dan efisien \\
\hline PP3 & Proses produksi di perusahaan selalu berjalan dengan stabil \\
\hline
\end{tabular}

c. Hubungan Pemasok dengan perusahaan merupakan hal penting untuk menjaga ketersedian bahan baku [9]. Jika persediaan bahan baku tercukupi maka perusahaan akan mudah memenuhi permintaan konsumen/pelanggan. Pernyataan hubungan pemasok (HPM) dapat dilihat pada Tabel 7.

Tabel 7. Pernyataan Hubungan Pemasok

\begin{tabular}{|c|l|}
\hline Kode & \multicolumn{1}{|c|}{ Pernyataan } \\
\hline HPM1 & $\begin{array}{l}\text { Perusahaan kami membuat kontrak kerjasama dengan pemasok } \\
\text { minimal lima tahun }\end{array}$ \\
\hline HPM2 & $\begin{array}{l}\text { Perusahaan kami senantiasa mengutamakan kualitas sebagai kriteria } \\
\text { utama dalam memilih pemasok. }\end{array}$ \\
\hline HPM3 & $\begin{array}{l}\text { Perusahaan kami senantiasa mengikutsertakan pemasok dalam } \\
\text { membuat sebuah perencanaan strategi. }\end{array}$ \\
\hline HPM4 & $\begin{array}{l}\text { Perusahaan kami membantu (memberi masukan) kepada pemasok } \\
\text { dalam meningkatkan kualitas produk. }\end{array}$ \\
\hline
\end{tabular}




\section{HASIL DAN PEMBAHASAN}

Data yang didapatkan dari penyebaran kuesioner yaitu sebanyak 40 karyawan yang mengisi kuesioner sesuai dengan persepsi mereka, selanjutnya data karyawan yang telah didapatkan dianalisis menggunakan metode analisis korelasi pearson dan menggunakan perangkat lunak analisis data $R$ studio. Berdasarkan perhitungan analisis korelasi yang dilakukan maka didapat hasil pada Gambar 1.

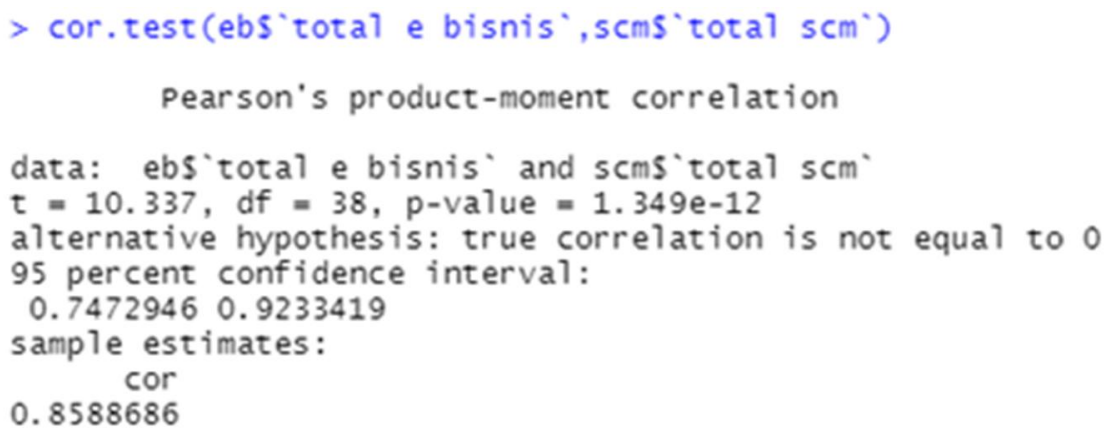

Gambar 1. Hasil Analisis Korelasi Pearson E-Business dengan SCM

Gambar 1 menghasilkan analisis korelasi pearson e-business dengan SCM. Antara variabel dependent dan independent memiliki korelasi sebesar $85 \%$, artinya ada hubungan positif yang kuat antara E-Business dan SCM yang digunakan pada PT Tsabita Cake \& Bakery.

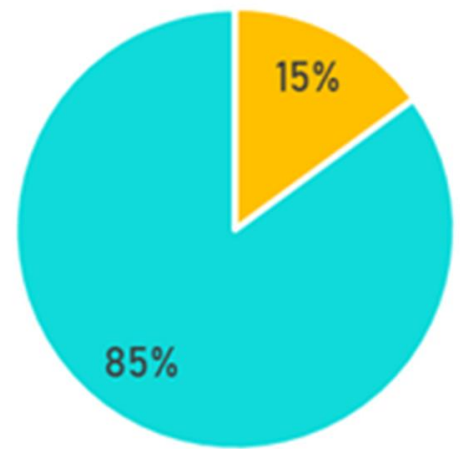

Gambar 2. Grafik Hasil Analisis Korelasi E-Business dan SCM

Gambar 2 merupakan gambar diagram lingkaran dari hasil perhitungan dengan menggunakan analisis korelasi. Perhitungan tersebut dihasilkan berdasarkan beberapa dimensi atau faktor yang ditentukan dari berbagai literatur yang kemudian menghasilkan $85 \%$ hubungan antara e-business dan SCM. Selanjutnya $15 \%$ sisanya merupakan pengaruh dari faktor-faktor lain diluar dimensi yang kita tentukan.

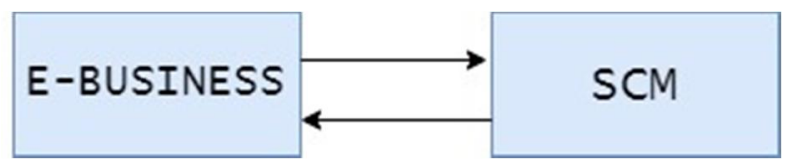

Gambar 3. E-Business dan SCM Saling Mempengaruhi 
Gambar 3 merupakan gambaran dari e-business dan SCM yang saling mempengaruhi satu sama lain. E-business memiliki fungsi untuk mendukung bagian marketing, produksi, akuntansi, keuangan dan sumber daya manusia dan SCM memiliki fungsi memanajemen aktifitas proses $e$ business sesuai dengan model teori yang ada sehingga hasil akhirnya adalah penerapan teknologi informasi memiliki peraanan penting dalam proses $e$-business.

Pada proses hubungan pelanggan dan perusahaan, perusahaan dapat menjalin komunikasi dengan pelanggan sehingga perusahaan mengetahui keinginan pelanggan, terkait kebutuhan serta tanggapan (feedback) dari para pelanggan. Hubungan dengan pelanggan ini perlu dijaga untuk menciptakan komunitas pelanggan yang loyal serta prospek jangka panjangnya, menilai dari produknya serta sebagai acuan inovasi produk baru kedepan. sehingga memudahkan perusahaan dalam mendistribusikan informasi mengenai produk baru.

Faktor administratif yang berhubungan dengan akuntansi keuangan dan manajerial erat kaitanya dengan Supply Chain Management. Berkaitan dengan komputerisasi atau penerapan teknologi informasi dalam pengolahan data konsumen, data pemasok, dan data karyawan. Implementasi teknologi ini akan memberikan dampak yang baik pada perusahaan karena datadata yang dibutuhkan dapat terorganisir dengan baik serta mudah untuk melakukan evaluasi. Proses produksi pada sebuah perusahaan memiliki kaitan erat dengan SCM dan e-business. Proses produksi yang baik akan memikirkan bagaimana perusahaan dapat mengolah limbah sehingga tidak mencemari lingkungan. Perusahaan perlu memastikan proses produksi berjalan dengan efektif dan efisien. Penerapan e-business dan SCM pada PT Tsabita Cake \& Bakery mempengaruhi hubungan dengan pemasok, untuk memastikan ketersedian bahan baku diperlukan kerjasama yang baik pada setiap pemasok dalam menentukan bahan baku untuk memberikan produk yang berkualitas.

\section{SIMPULAN}

Supply chain management pada PT Tsabita Cake \& Bakery meliputi perencanaan dan pengelolaan dari semua kegiatan yang terlibat dalam sumber dan pengadaan, konversi, dan semua kegiatan logistik manajemen. Berbagai tahapan SCM secara umum adalah supplier, produksi, distributor dan customer. PT Tsabita Cake \& Bakery sudah menggunakan SCM dimulai dengan pemilihan supplier dalam pengadaan bahan baku. Kemudian bahan baku diproduksi. Selanjutnya setelah menjadi bahan jadi diberikan kepada tim distributor dan dilanjutkan pengiriman kepada customer. Perusahaan melakukan reorder kepada supplier yang berkomitmen menyediakan bahan baku tepat waktu. Reorder tersebut sudah tersistem otomatis melalui sistem E-business pada PT Tsabita Cake \& Bakery. Jika beberapa produk di toko cabang habis maka langsung otomatis terlihat pada sistem repository perusahaan. Sehingga tanpa pemberitahuan via telepon pun dengan sigap langsung dapat dilakukan pendistribusian pada toko-toko yang sudah hampir kehabisan roti. Dari berbagai kegiatan yang tersistem tersebut maka PT Tsabita Cake \& Bakery memiliki nilai efisiensi lebih setelah menggunakan $e$ business dan SCM. Efisiensi tersebut berpengaruh pada manajemen internal perusahaan sehingga dapat meningkatkan profit perusahaan.

Dari penggunaan e-business dan SCM yang sudah diterapkan pada PT Tsabita Cake \& Bakery lalu dilakukan penelitian dengan tujuan untuk mengetahui pengaruh penerapan ebusiness dan SCM pada PT Tsabita Cake \& Bakery yang pada akhirnya didapatkan hasil antar variabel memiliki korelasi antara $85 \%$, artinya ada hubungan positif antara $e$-business dan SCM yang digunakan pada PT Tsabita Cake \& Bakery.

Berdasarkan hasil diatas dapat disimpulkan bahwa e-business dan SCM pada PT Tsabita Cake \& Bakery memiliki pengaruh hubungan positif pada perusahaan tersebut. Selanjutnya 
bagaimana cara stake holder pada perusahaan tersebut melakukan pengawasan yang baik terhadap sistem yang ada maupun terhadap karyawan sebagai user sistem tersebut.

\section{SARAN}

Saran yang dapat diberikan pada penelitian Hubungan E-Business dan SCM dalam Manajemen Internal PT Tsabita Cake \& Bakery:

1. Untuk Penulis agar lebih banyak membaca referensi-referensi jurnal agar memiliki cakupan yang lebih luas dalam melakukan penelitian dan penulisan jurnal ilmiah.

2. Terhadap Akademis agar lebih banyak mengadakan seminar atau workshop terkait penelitian dan penulisan jurnal.

3. Untuk peneliti yang akan melanjutkan penelitian berikutnya diharapkan dapat menentukan faktor-faktor yang lebih luas lagi seperti hubungan jangka panjang dengan pemasok dan pelanggan. Hubungan jangka panjang disini mempunyai tujuan untuk mendapatkan dan mempertahankan konsumen.

4. Bagi pihak perusahaan agar lebih terbuka serta bersikap kooperatif dengan adanya penelitian-penelitian yang akan dilakukan oleh mahasiswa. Hal ini tentunya akan saling menguntungkan. Mahasiswa merasa terbantu sesuai dengan tujuan penelitian sedangkan bagi pihak perusahaan dapat memanfaatkan kesempatan tersebut sebagai ajang promosi produk yang dimiliki.

\section{UCAPAN TERIMA KASIH}

Penulis mengucapkan terima kasih kepada:

1. Prof. Dr. Eko Sediyono, M.Kom dan Dr. Aris Puji Widodo, S.Si., MT selaku pembimbing dalam melakukan penelitian hingga penulisan jurnal ini.

2. Terima kasih kepada rekan - rekan Sekolah Pascasarjana Sistem Informasi Universitas Diponegoro Semarang yang telah memberikan dukungan moril selama proses penelitian berlangsung.

3. Terima kasih juga penulis sampaikan kepada Owner PT Tsabita Cake \& Bakery, seluruh staf produksi, marketing, staff IT, dan stakeholder terkait yang telah mengijinkan proses penelitian ini berlangsung.

4. Terima kasih kepada orang tua penulis atas doa yang diberikan sehingga proses penelitian ini bisa selesai tepat waktu tanpa ada kendala.

5. Terima kasih kepada tim review jurnal JATISI selaku penyelenggara penerbitan jurnal.

\section{DAFTAR PUSTAKA}

[1] Sugiyono. 2013, Metode Penelitian Kuantitatif, Kualitatif dan $R \& D$, Alfabeta, Bandung.

[2] L. Whitten, Jeffrey, \& D. Bentley, Lonnie. 2007, System Analysis\& Design Methods Seventh Edition. New York, USA :McGraw-Hill.

[3] Stoole, Christoper, 2000, E- business - Just What is It?

[4] Turban, Leidner, McLean, and Wetherbe, 2008, Information Technology for Management, 6th ed.: John Wiley \& Sons (Asis) Pte Ltd. 
[5] Arumugam, V.C and Mojtahedzadeh, R. Measuring Customer Satisfaction with Service Quality Using American Customer satisfaction Model (ACSI Model), International Journal of Academic Research in Business and Social Science, 2011, Vol.1 No 3, pp. 232-258.

[6] David Simchi-Levi,. 2000, Designing And Managing The Supply Chain, Mc Graw -Hill Companies Inc, United States of America.

[7] Kalakota, Ravi \& Maria Robinson, E-Business 2.0: Roadmap for Success, AddisonWesley, Longman Inc., USA.

[8] Gunarto, Thomas Yuni. 2015, Hubungan Tingkat Pendidikan Dengan Preferensi Pemilihan Model Bisnis Toko Online, Jurnal Ekonomi Bisnis Volume 20 No. 1.

[9] Nykamp, Melinda. 2001, The Customer Differential: The Comple Guide to Implementing Customer Relationship Management, Amacom, New York.

[10] Suhari, Y., 2011, Peran Teknologi Informasi Dalam Rantai Pasokan, Jurnal Dinamika Informatika, 3(2).

[11] Yamit, Zulian. 2011, Manajemen Produksi \& Operasi (Edisi Pertama), Ekonisia, Yogyakarta.

[12] Wu Fang, Mahajan Vijay \& Sridhar Balasubramanian, 2003, An Analysis of E-Business Adoption and its Impact on Business Performance, Journal of The Academy of Marketing Science. Volume 31, No. 4, pages 425-447. 